\title{
ARTÍCULOS
}

\section{REDISTRIBUCIÓN RITUAL EN UNA EXPRESIÓN FESTIVA POPULAR. LA FIESTA DE VERDIALES DE LOS MONTES DE MÁLAGA}

\author{
RITUAL DISTRIBUTION AT A POPULAR FESTIVE EXPRESSION. \\ FIESTA DE VERDIALES IN THE MONTES OF MÁLAGA
}

\author{
Francisco Manuel Llorente Marín ${ }^{1}$ \\ Universidad de Málaga
}

\section{Evelina Zurita Márquez²}

Universidad de Málaga

Recibido: 3 de enero de 2020; Aprobado: 3 de noviembre de 2020.

\begin{abstract}
Cómo citar este artículo / Citation: Llorente Marín, Francisco Manuel y Evelina Zurita Márquez. 2021. “Redistribución ritual en una expresión festiva popular. La fiesta de verdiales de los montes de Málaga". Disparidades. Revista de Antropología 76(2): e026. doi: <https://doi.org/10.3989/dra.2021.026>.
\end{abstract}

RESUMEN: Este artículo aborda una investigación realizada sobre la Fiesta de Verdiales, una expresión festiva popular localizada en el espacio ecológico-cultural de los Montes de Málaga. Acometemos esta indagación desde el análisis o descomposición de la doble dimensión de la acción humana, en cuanto instrumental y expresiva, inspirada en las tesis sobre teoría de la comunicación de la Escuela de Palo Alto. Los sujetos sociales no sólo se enfrentan al mundo para sobrevivir. La interpretación de las culturas nos muestra el gozoso esfuerzo en que se alzan por encima de sí mismos, a través de formas de expresión que transfiguran lo que su realidad es. En la Fiesta, como comunicación y expresión de la comunidad, es decir de lo común, se construyen formas de relación social que van a contrapelo de lógicas hegemónicas individualistas, de la rentabilidad y el consumo. La Fiesta es una plataforma que invita a imaginar la Realidad hecha añicos.

PALABRAS CLAVE: Acción instrumental y expresiva; Ritual; Fiesta de Verdiales; Redistribución.

ABSTRACT: This paper addresses a research conducted on la Fiesta de Verdiales, a popular festive expression celebrated in the ecological-cultural area of the Montes of Málaga. This research is based on the analysis of the human actions as having a double dimension, one related to music and instruments and the other, related to the expressions. This study has been inspired by the communication theses of Palo Alto School. Social subjects do not only confront the world to survive. As shown by several studies that interpret cultures, humans, as social beings, also confront what they are through different forms of expressions which transform their reality. At the Fiesta, understood as a mean of expression and communication

1 Correo electrónico: Ilorente@uma.es. ORCID iD: <https://orcid.org/0000-0001-5144-884X>.

2 Correo electrónico: zurita@uma.es. ORCID iD: <https://orcid.org/0000-0002-7086-6593>. 
of a community, forms of social relationships are constructed opposing to the hegemonic individualistic, profitability and consumption logics. The Fiesta recreates an atmosphere that invites us to imagine a Reality broken into pieces.

KEYWORDS: Instrumental and Expressive Action; Ritual; Fiesta de Verdiales; Redistribution.

\section{CONTEXTO INTRODUCTORIO}

Sostiene Harvey Cox (1983) que los sujetos humanos no sólo trabajan y piensan, sino que cantan, bailan, cuentan historias, festejan, son homo festivus. La Fiesta de Verdiales ${ }^{3}$ es una de esas expresiones populares. El ritual es la repetición institucionalizada de conductas expresivas ancladas en la memoria. Los rituales se mantienen en tiempos y lugares como formas de expresión popular por su imbricación con la toposensitividad, es decir, por su vinculación con espacios ecológicos, familiares, cotidianos o de celebración (por ejemplo la venta, el lagar, los Montes en la Fiesta de Verdiales), pero también por su imbricación con la temposensitividad: ciclos estacionales, ciclos festivos (navidad, carnaval, cruces de mayo), así como ciclos asociados a la actividad productiva (periodos de siembra, periodos de cosecha) (Gil Calvo 1991).

El espacio ecológico-cultural e histórico de esta Fiesta se localiza en los Montes de Málaga. Los Montes -topónimo de localización de un pago o partido cargado de simbolismo-, son unas estribaciones montañosas que rodean de forma semicircular la ciudad de Málaga, con las que ha tenido una relación geográfica e histórica de la que hablamos puntualmente a lo largo del artículo. Su delimitación es ambigua y confusa, y no se corresponde con unos límites administrativos precisos.

En los Montes de Málaga, desde finales del siglo $\mathrm{XV}$ y principios del siglo $\mathrm{XVI}$, comienza una intensa desforestación que transforma su suelo en tierras de labor, tierras que se dedican fundamentalmente al cultivo de la vid, no solo para la producción de vino, sino también para la producción de la pasa. La producción vitivinícola era tal que «en algunos partíos como Guadalmedina, Santa Catalina y Venta Larga se contabilizaron en 1896 más de 6 lagares por kilómetro cuadrado» (Blanco 1997: 49). El lagar tenía

3 Cuando en este documento aparece «Fiesta», en mayúscula, nos estamos refiriendo a la Fiesta de Verdiales y con «fiesta», en minúscula, a cualquier expresión festiva en general.

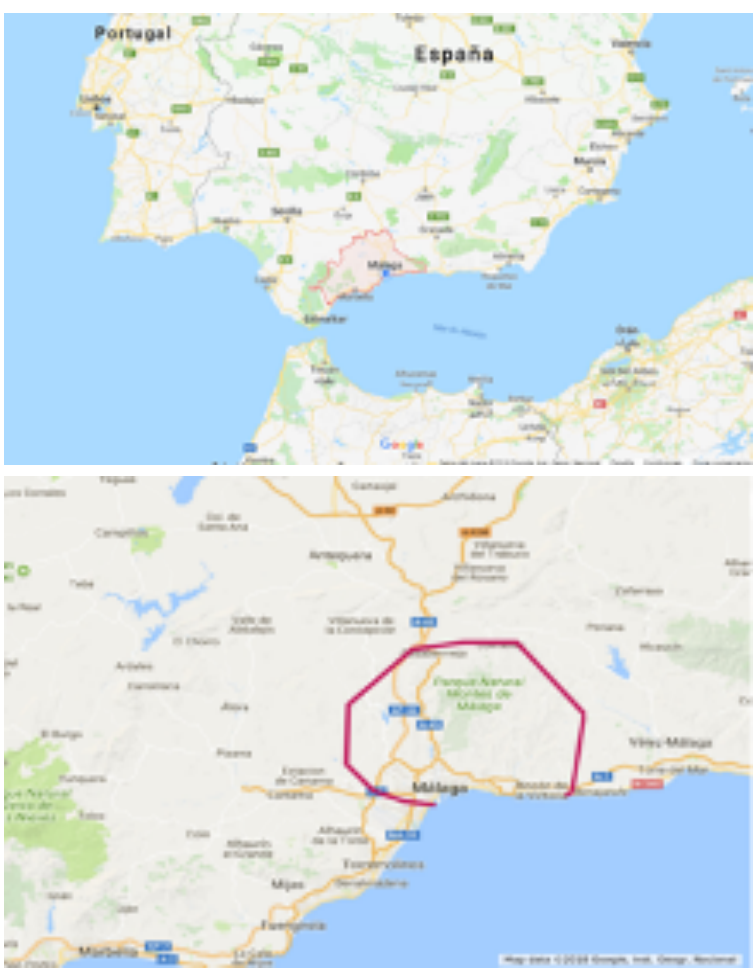

FIgURAS 1 y 2.-- Localización de Los Montes de Málaga. Fuente: Google Maps. Delimitación propia.

diferentes funciones que no se reducían únicamente a la producción de vino, "también estaba constituido por la vivienda, cuadras, establos, almacén» (Blanco 1997: 109). Por otro lado, este espacio era lugar de encuentros familiares, de vecinos, un lugar de socialización de niños y jóvenes, de celebraciones de final de cosechas, de la pisa de la uva y de rituales como la Fiesta de Verdiales.

La población de los Montes de Málaga era una población campesina dependiente de la oligarquía malagueña que vivía en la ciudad. El hábitat de los Montes era disperso, con una estructura de la propiedad fundamentalmente minifundista. El mayor crecimiento demográfico en este territorio se dio desde el siglo XVIII hasta finales del XIX. El desarrollo económico que convirtió a Málaga en un núcleo comercial muy importante del Mediterráneo hasta finales del siglo XIX, había promovido una densa red de comunicaciones de caminos de arriería en los 
Montes, centrada fundamentalmente en el comercio (Gómez y Blanco 2010). Esto supuso un incremento del número de ventas en estos caminos. Las ventas, en los Montes de Málaga, se instituyen no solo como lugares de paso, descanso y avituallamiento, sino también como lugares de fuerte sociabilidad y encuentro festivo. Las ventas eran espacios de celebraciones rituales como la Fiesta de Verdiales. Viajeros del siglo XVIII, como Francis Carter, llegaron a describir rituales de final de cosecha en los Montes de Málaga como "costumbres paganas que se conservaron desde la época de los romanos» [saturnalia romanas] (Mandly 1996: 46-47). Alberto del Campo, afirma que esta y otras fiestas del periodo de invierno en las que están presentes los bailes, los juegos, las bromas, las coplas, las diversiones alocadas de inversión de roles (que podemos denominar "carnavalescas»), desde antiguo se ha considerado que tienen reminiscencias paganas vinculadas a las saturnales romanas ${ }^{4}$, a las Kalendae de enero y a las "libertades de diciembre» de las que habla Horacio (Del Campo 2020).

La Fiesta debemos rastrearla más allá de los límites territoriales de los Montes, siguiendo el importante camino de arriería que ya en el siglo XV transcurría desde los pagos de Almogía (a su Poniente), hasta Comares (a su Levante), por los Campos de Cámara. De hecho, desde sus distintos modos de expresión en toque, baile y cante ${ }^{5}$, las tres modalidades de Fiesta de Verdiales que existen, simbolizan también esta extensión ecológico-cultural aludida.

El auge económico en los Montes de Málaga se frenó a finales del siglo XIX debido a la crisis que trajo consigo la plaga de la filoxera de la vid. Esta crisis se prolongó durante décadas hasta más allá de la mitad del siglo XX. A partir de los años 60, al calor de las construcciones que iniciaban el boom turístico de la Costa del Sol malagueña, la mayor parte de la población campesina de Los Montes bajó a trabajar e instalarse en la ciudad, fundamentalmente, en la construcción y el turismo. Esta población fue a

4 Esto no quiere decir que toda manifestación festiva carnavalesca tenga un entronque con estas fiestas paganas de la antigüedad.

5 Así, las modalidades de Almogía y de Comares se manifiestan, incluso, en formas expresivas más barrocas que la de Montes, si seguimos la denominación de los conceptos fundamentales de historia del arte de Wölfflin (1979).

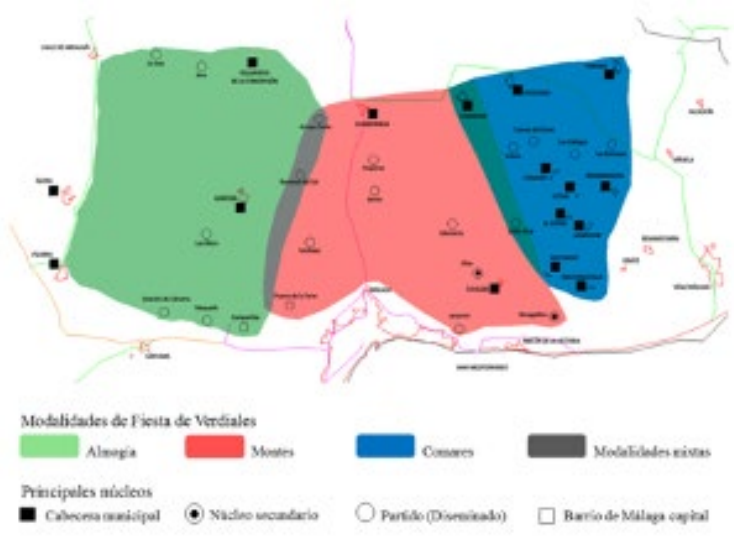

FiguRA 3.- Ámbito territorial histórico de las modalidades de la Fiesta de Verdiales. Elaboración propia.

asentarse en la periferia constituyendo el grueso de los habitantes de barrios malagueños como el Puerto de la Torre, la Mosca, la Pelusa y Mangas Verdes. En estos barrios siguen viviendo familias enteras descendientes de antiguos habitantes de Los Montes y en ellos siguen manteniendo una vinculación fuerte con este espacio ecológico y simbólico y sosteniendo estos rituales festivos.

El Ayuntamiento de Málaga decidió en 1989 trasladar la Fiesta Mayor del 28 de diciembre de la venta del Túnel, en plenos Montes, a la venta San Cayetano, una venta de las de la salida del barrio del Puerto de la Torre. En la última década se emplaza la Fiesta en el casco del barrio, dando vida a multitud de restaurantes y bares del mismo. En esta celebración participan hasta treinta pandas ${ }^{6}$ de Málaga y su provincia que atrae a muchos fiesteros y amigos de la Fiesta pero, curiosamente, a muy pocos turistas. En esta celebración, como en otros eventos, a ojos de los visitantes, aparentemente, prevalece el espectáculo por la presencia del escenario, evolucionando la Fiesta desde sus aspectos más externos; sin embargo, aún en este tipo de celebraciones, se mantiene el

6 En Málaga y provincia en la actualidad están activas, aproximadamente, este número de pandas. No todos los componentes de una panda pertenecen a una misma localidad o barrio. El nombre de las pandas suelen referir: topónimos (por ejemplo, Santón Pitar, Jotrón y Lomillas, Arroyo Conca, La Axarquía, La Primera de Los Montes, Los Baños del Carmen, etc.); localidades (por ejemplo, Benagalbón, Moclinejo, Los Romanes, etc.), o lleva el nombre de su alcalde (como la de Isabel Portillo, la de El Negocio, la de El Capitán, etc.). 
fundamento del ritual y sus significaciones en el tiempo no espectacular.

\section{METODOLOGÍA}

Esta investigación propone acercarse a la Fiesta de Verdiales desde los análisis que la Escuela de Palo Alto sostiene sobre la distinción de comunicación instrumental y comunicación expresiva (Bateson 1998 y Watzlawick 2002). Trasladamos estos análisis a la actividad humana, entendiendo que esta tiene ambas dimensiones. Así, abordamos «la fiesta como ritualización del comportamiento expresivo» (Gil Calvo 1991: 157), es decir, como expresión de la comunidad. Por otra parte, analizamos los comportamientos expresivos y comunicativos de fiesteras y fiesteros de Verdiales como aquellos que posibilitan crear nuevas relaciones sociales en el momento en el que se están generando como actividad expresiva.

La investigación comienza de un modo formal en el año 2017, aunque en años previos se producen tomas de contacto con la Fiesta y las primeras incursiones de campo con entrevistas informales. La investigación se prolongó hasta septiembre de 2019.

Esta investigación utiliza una metodología cualitativa fundada en un trabajo de campo etnográfico en el que se han realizado 27 entrevistas en profundidad semidirectivas y 44 entrevistas informales de carácter abierto. También hemos realizado observación interna participante y observación no participante con criterios de sistematización media-baja (Rubio y Varas 1999). Para ello ha sido fundamental la participación activa en los rituales propios de esta expresión festiva, en la que maestros fiesteros y fiesteras nos han servido como informantes bisagra.

La elección de nuestros informantes se realizó a través de la técnica de muestreo «bola de nieve». El criterio para la selección de la muestra ha sido la pertinencia de los informantes para la investigación teniendo en cuenta: a) su cualidad de fiestero/a, o amigos de la Fiesta, b) su participación o no en pandas formales e informales, c) la edad, sexo y estrato social, d) el tiempo que llevaba incorporado a la Fiesta, y e) si enseñaba o no Fiesta.

Hemos optado por una muestra amplia y variada que abarcara los criterios arriba indicados. Los informantes (franja de edad de entre 7 y 70 años) han sido: fiesteros/as ${ }^{7}$ maestros ${ }^{8}$ ( 6 varones y 2 mujeres) y no maestros (18 varones y 8 mujeres); amigos de la Fiesta ${ }^{9}$ aficionados (15 varones y 6 mujeres), familiares de fiesteros y fiesteras ( 6 mujeres y 3 varones), personas que se acercan a la Fiesta (1 mujer y 1 varón); investigadores de la Fiesta (4 varones y 1 mujer $)^{10}$

La técnica de la entrevista la consideramos fundamental en todo proceso de investigación etnográfica. En nuestro caso, la entrevista en profundidad nos ha permitido indagar en las expresiones populares, más que buscando su raíz, más que focalizando la atención en su conservación, conversando con ellas. Hemos explorado contextos de significación en los que cobran sentido las expresiones sociales del grupo $y$, algo muy importante, en esta conversación que hemos mantenido con nuestros informantes, la expresión festiva nunca ha sido desligada, separada, ni vista como un artificio, como algo que queda fuera de la vida social del grupo, de la comunidad, en definitiva, de la vida de las fiesteras y de los fiesteros. Las entrevistas en profundidad y la observación realizadas nos han permitido comprender que la realidad social y sus manifestaciones tienen capas. El lenguaje, más allá de sus funciones de transmisión e información, puede también crear relaciones a través de la comunicación, y esta capacidad no es algo lineal ni admite la fragmentación en unidades semióticas mínimas. Estamos de acuerdo con la propuesta de

7 Son fiesteros/as quienes pertenecen formal o informalmente a una panda.

8 Son considerados maestros aquellos fiesteros/as que enseñan Fiesta en escuela de Verdiales o en la Fiesta propiamente dicha.

9 Nombramos con esta expresión a aficionados, familiares de fiesteros y fiesteras y personas que se acercan a la Fiesta.

10 Esta asimetría de varones y mujeres informantes en la muestra responde en la actualidad a una desigual participación: En la instrumentación los «tocaores» son en su mayoría varones (no obstante, hay excepciones pues incluso encontramos pandas constituidas solo por mujeres "tocaoras»); al cante encontramos tanto varones como mujeres en una proporción más equilibrada; en el baile encontramos, con diferencia, más mujeres que varones; los alcaldes, salvo excepciones, suelen ser varones. En cuanto a familiares, aficionados y personas que se acercan a la Fiesta, la proporción de hombres y de mujeres es más equitativa. 
"giro semiótico» de Paolo Fabbri, cuando apunta a que el lenguaje y sus formas «tienen espesor», son como un «hojaldre» (2004: 42) en el que las capas no están puramente superpuestas, no admiten una fragmentación quirúrgica, sino que exigen un acercamiento analítico omnicomprensivo.

Las entrevistas en profundidad y la observación participante la hemos desarrollado en los siguientes contextos de significación:

a) En la escuela de Verdiales ${ }^{11}$ Nuestra Señora de los Dolores, ubicada en el barrio malagueño de Mangas Verdes. Para realizar esta observación participante nos convertimos en alumnos, recibiendo enseñanzas de maestros y maestras fiesteras. El método de aprendizaje de esta escuela se funda en las lógicas de la transmisión oral, quedando fuera las lógicas de la escritura (pentagramas, conocimientos académicos musicales, titulaciones, certificaciones de maestros fiesteros, etc.). Hemos acudido a clases de platillos, de pandero y de cante durante tres años.

Como señalamos en el contexto introductorio, a partir de los años 60 la mayor parte de la población de Los Montes baja a trabajar e instalarse en la ciudad. El barrio de Mangas Verdes, por su ubicación y urbanización, representa simbólicamente Los Montes en la ciudad de Málaga. Elegimos este barrio y la escuela de verdiales allí ubicada por ser uno de los espacios urbanos más representativos de la vinculación entre sus habitantes, contexto ecológico y estos rituales festivos.

b) Participación en fiestas oficializadas como festivales y concursos de verdiales: en la provincia de

11 De las nueve escuelas de verdiales que existen en Málaga solo siete están activas en el año 2020. De la modalidad de Montes las escuelas actuales son: Puerto de la Torre, Huelin, Nuestra Señora de los Dolores, Montes de Málaga y La Mosca. De la modalidad de Almogía: Huertecilla de Mañas, La Copla; y de la modalidad Comares: las Castañetas y Peña los Verdiales (estas dos últimas no activas). En la provincia de Málaga existen unas ocho escuelas más en las que fluctúan su actividad, o no, dependiendo de que, en cada curso, tengan o no alumnos. Estas escuelas de verdiales reciben subvención de los Ayuntamientos y de la Diputación de Málaga. Si bien las escuelas suponen una cierta patrimonialización de la Fiesta, el hecho de que sigan la lógica de la transmisión oral y de las relaciones de comunidad orientadas a la Fiesta, lo consideramos de un gran valor etnográfico a la hora de estudiar estos rituales.
Málaga ${ }^{12}$, en ventas próximas a Málaga ${ }^{13}$ y en Málaga capital: la Fiesta Mayor de Verdiales o día de los Tontos (28 de diciembre), la Fiesta de los Mosaicos, con un fuerte arraigo en el barrio de Mangas Verdes (celebrada en días previos a la Navidad).

c) Participación en fiestas familiares y de amigos, tales como fiestas de "arrejuntaos», noches de San Juan y días de Navidad (celebradas en ventas el 25 de diciembre).

d) Participación en cursos de creación e improvisación de letras de Verdiales para coplas.

e) De forma particular, hemos realizado observación en contextos académicos y de investigación, participando tanto como ponentes y asistentes, en Congresos y Jornadas referidos a la Fiesta de Verdiales.

La observación no participante la desarrollamos específicamente en momentos festivos, encuentros y concursos de pandas, festivales y en otras escuelas de Verdiales localizadas en dos barrios de la ciudad de Málaga, La Mosca y El Palo.

\section{RESULTADOS DE INVESTIGACIÓN}

\section{LA FIESTA COMO EXPRESIÓN Y COMUNICACIÓN DE LA COMUNIDAD}

Desde Turner (1998) y sus análisis, sabemos de la función de cohesión social que proporcionan a la comunidad los rituales. Perola fiesta, además, «implica transfigurar la vida social en vida pública [...]. La vida pública es la vida social más su autorepresentación reflexiva» (Gil Calvo 1991: 11). Las fiestas, con sus rituales, comunican en un doble sentido: se comunica la comunidad, se autoreferencia, se habla a sí misma y también «se habla» con otras comunidades, barrios, pueblos, ciudades.

12 Destacamos el concurso de Benagalbón por varias razones: primero porque es el concurso que recuperó y mantiene el choque de pandas, en segundo lugar, porque en la actualidad es el momento de la Fiesta de Verdiales más grande que se da en Málaga y su provincia en la modalidad de Montes y, en tercer lugar, es el primero que recoge el concurso de copla «levantá».

13 "Concurso de "arrejuntaos"» en Venta Álvaro, “Concurso de Verdiales estilo Montes» en Venta Españita. 
En nuestro caso, cuando hablamos de Fiesta de Verdiales, entendemos un proceso expresivo de encuentros, toque, cante, baile, bromas, inversión, ironía, juegos de lenguaje ${ }^{14}$. "Ir de Fiesta», en el decir de los fiesteros, es asistir y participar en este proceso ritual constituido en un "hecho social total», en el sentido que le da Mauss (2009), pues expresa a la vez, y de un golpe, relaciones institucionalizadas diversas: sociales, morales, estéticas, económicas. Hablamos de encuentros de amigos, familias, conocidos, que se unen en pandas ${ }^{15}$, formales o no, y que a través de la música (en forma de $\operatorname{coplas}^{16}$ y baile ${ }^{17}$ ) presentan formas de expresión antiquísimas que se han ido impregnando de elementos de diferentes culturas a lo largo de los siglos (Mandly 1996 y 2010; Molina 2010). La Fiesta de Verdiales es una expresión festiva no establecida en el calendario

14 El denominado "segundo Wittgenstein», en sus Investigaciones Filosóficas (2010), entendía "Juegos del Leguaje» como una totalidad conformada por el lenguaje y las acciones con las que está entretejido. Considera que el lenguaje va más allá de sí mismo, es una forma de vida y que tiene implicaciones múltiples, siendo para cada ocasión diferente. Lo determinante de los juegos del lenguaje es su uso.

15 Grupos de músicos populares que comparten ciertas semejanzas con agrupaciones para el ritual festivo de otras comarcas de España: "parrandas de inocentes» o "cuadrillas murcianas»; "rondas castellano-manchegas»; "ranchos de ánimas canarios», etc. Una panda de Verdiales, instrumentalmente, se compone de violín, guitarras, pandero, platillos (pequeños crótalos) y solo en la modalidad de Comares laúd y bandurria. Además de los instrumentos, forman parte de la panda, el alcalde (autoridad del grupo), caracola (anuncia la llegada de la panda), cantaores, bailaoras y bailaores (Molina 2010).

16 La copla es un fandango que conserva el formato de aquel que se extendió durante el siglo XVIII en casi toda España y parte de Europa. Las coplas de Verdiales se comienzan a entonar tras los primeros tanteos de afinación de la panda, que entra tocando al ritmo que le es propio, en compás de $3 \times 4$. Tras el «paseo» entra el cante y la «mudanza». Las coplas que se cantan son cuartetas octosílabas en las que se repite el segundo y quinto o primer verso hasta conformar seis, y si son quintillas octosílabas se repite el segundo verso. Una «lucha» se compone de tres o cuatro coplas, a criterio del alcalde. Una de las características más importantes de las coplas de verdiales es que solían ser inventadas, improvisadas al instante, trovadas o poetizadas. Las coplas se hacían de repente, se repentizaba (Molina 2010).

17 Se ejecuta en parejas o en la modalidad de "tresillos» (bailando un hombre y dos mujeres) que se formalizan de forma improvisada y tiene la estructura del llamado «paseo» y «mudanzas» (Molina 2010; Tomé 2010). litúrgico o secular, aunque goza de ciertos días "geniales o lúdricos» (Rodrigo Caro 1978) alrededor del solsticio de invierno (días próximos a la Navidad y durante esta). Es también un proceso expresivo que tiene reminiscencias campesinas en sus formas y contenidos. Pero, además, es una forma ritual que construye relaciones desde lógicas que no se alinean en muchos aspectos con las lógicas hegemónicas de nuestras sociedades.

La Fiesta de Verdiales presenta relaciones horizontales intergeneracionales, entre los sexos, entre grupos sociales, sin percibirse jerarquizaciones estipuladas en la participación del ritual. En ella, el individuo ${ }^{18}$ no cuenta, en el sentido de que las lógicas de la Fiesta siempre aluden al grupo, a lo común. Sin embargo, encontramos entre los fiesteros una valoración especial a los modos de ejecución de sujetos individuales en cante, toque o baile, de forma que una melodía, un toque o una ejecución de determinada mudanza de baile, se reconoce y nombra por el "aire» que le da un determinado fiestero o fiestera. Por ejemplo, el toque de violín de Povea o el cante de Lolita de Arroyo Adelfas. Cuando prevalece la lógica individual, como decía uno de nuestros informantes, "no hay Fiesta», o, «no hay panda». "No hay panda» es expresión colectiva de indeseabilidad que significa que el grupo, la panda, no está ejecutando como debiera, no está funcionando como grupo y, entonces, no hay Fiesta, no se puede producir la experiencia estética y social compartida que se desea y espera. Además, «nadie puede sobresalir, nadie puede imponerse a otro [...], si es así, no hay Fiesta». Esto que expresan nuestros informantes fiesteros va contra las lógicas individualistas de relación, porque el grupo prevalece $y$, si no es así, no puede tener lugar lo que se anhela. Nuestro trabajo de campo etnográfico reafirma de este modo que las conductas expresivas son algo más que "un decir», son, también, "un hacer», son una cópula para que lo común no se deje robar el aíre que le permite seguir viviendo.

En la Fiesta, simbólicamente, se toca y se canta en círculo. Los instrumentos están en una disposición

18 Entendemos "individuo» desde las propuestas de Dumont (1987), cuando alude a «ideología» individualista cuyos valores hegemónicos son los económicos de intercambio y donde las relaciones sociales son concebidas desde la lógica de las relaciones de las personas con las cosas. 

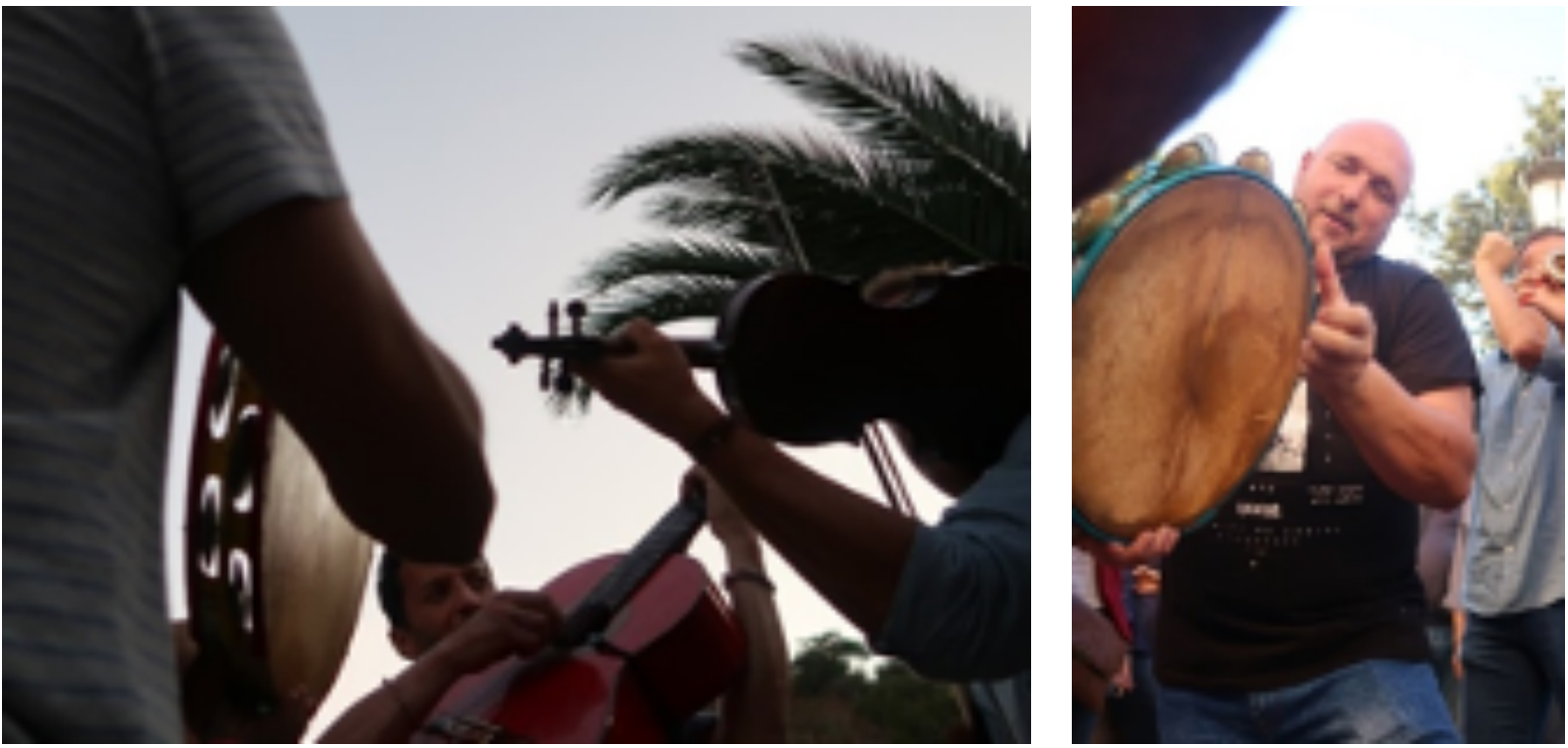

FIGURAS 4 y 5.- Ritual y círculo. Fotografías de Manuel Llorente y Evelina Zurita.

circular, aunque no de forma fija, pues los ejecutantes cambian de lugar, y a veces de instrumentos. El círculo es un símbolo casi cósmico. El círculo es la fuerza centrífuga de la panda. La llamada es siempre al círculo. El pandero, circular, está en el centro del círculo. Sobre ese círculo se agolpan cuidadosamente otros fiesteros y amigos de la Fiesta conformando círculos concéntricos. El modo de vivir y disfrutar de la Fiesta tiene su locus o lugar exacto formando parte de esos círculos (representación simbólica de lo comunitario). Según Tomé (2010: 76), «los fiesteros antiguos, cuando se daban cuenta que estaba a punto de bailar una pareja muy reconocida (por cómo bailaban), le abrían el círculo para que bailaran en el centro de él. Eso para una bailaora es lo más grande y rara vez ocurre».

La Fiesta es un momento privilegiado de redistribución (de prestigio, de habilidades, de recursos, de posiciones...), porque para recibir hay que dar. No hay diversión en la Fiesta sin este proceso de redistribución. Se redistribuye con cante, baile, miradas, bromas, risas, y también comida, dinero $\left(\right.$ rifas $\left.^{19}\right)$. En la redistribución ritual el que no tiene otra

19 En la rifa se pone en juego el ingenio y agudeza jocosa de presentes y aficionados. A la panda se le ofrece una cantidad de dinero, obligándola con ello a realizar alguna acción trasgresora que subvierte y pervierte el orden, pero siempre en un sentido cómico y divertido, por ejemplo, echar unas luchas de Fiesta en un corral de cabras en pleno mes de diciembre en Los Montes; o echar un revezo de rodillas todos los fiesteros. En las cosa canta, anima, pone dinero en la rifa, el dueño de la casa pone comida, etc. Esta redistribución tiene mucho que ver con los ciclos de la cultura campesina, como los remates de la cosecha, y va muy asociada a la carnavalización ${ }^{20}$. A través del honor, según Pitt-Rivers, se trata de conseguir prestigio social derrochando lo que se ha adquirido, pues el honor mediterráneo deriva de la redistribución "y ese es el fin que distingue los valores adquisitivos en Andalucía. No hace falta decir que es un fin reñido con la acumulación capitalista» (1979: 66).

Uno de los ejes de la Fiesta de Verdiales entronca directamente con uno de sus orígenes históricos, las saturnales romanas y sus rituales de inversión social. A partir del siglo XVII, lo cómico, recala en un cierto estatismo y costumbrismo frente a la esencia de la risa y lo grotesco que nace de la contradicción, la ambivalencia, la constante imperfección de la existencia, el sentido del vaivén existencial. El racionalismo no podía comprender la vida cotidiana formada en medio de contradicciones ni concebida como inconclusa (Bajtín 2003).

rifas siempre se rebasan ciertos límites, pero nunca se traspasa completamente el orden.

20 Entendida la carnavalización no sólo como el carnaval oficializado, sino también como esas formas de expresión que son formas de inversión, de liberación del orden hegemónico, libera de frustraciones individuales $y$, sobre todo, colectivas. 
La inversión carnavalesca ${ }^{21}$ está presente en la Fiesta ya en el mismo modo en el que los fiesteros son llamados y se llaman a sí mismos "tontos», "locos», en el ciclo de Navidad, especialmente el día de los Tontos (28 de diciembre, celebración de la llamada «Fiesta Mayor de Verdiales»). En este ciclo, y en este día, es imprescindible que los fiesteros vayan ataviados con su peculiar sombrero. Este elemento de su atuendo, forrado de tela, está cubierto completamente de flores de diversos y vivos colores acompañadas de cuentas de perlas colgantes, campanitas, broches, medallas. Uno de los elementos más llamativos son los espejitos, unas veces pegados al sombrero y otras colgando de él, que tenían como función «alumbrar y reflejar el sol por barrancos y torrenteras [...]. Las cintas o lazos, expresión indiscutible de tiempo o ciclo de carnaval» (Mandly 2010: 43), les cuelgan hasta la cintura a los «tontos» o «locos», cubriendo hombros y espalda.

"Loco», en la tradición popular de occidente, es un término con significaciones ambivalentes, está unido a la idea de los bufones, a lo cómico popular, a lo carnavalesco (Bajtín 2003).

«Todo esto vemos hoy, especialmente en las aldeas, donde todo el día de los Santos Inocentes, que concurre en el mismo tiempo en que antiguamente celebraban las saturnales, la gente rústica hace semejante disparate, poniéndose carátulas y echan coplas de repente». (Rodrigo Caro 1978: 210)

Los Tontos, los Locos, los Catetos, son los que llevan la voz cantante de forma muy evidente, mandan en la Fiesta de Verdiales, marcan sus tiempos, tiempos que van bastante a contramano de la cuantificación, de la velocidad, de la inmediatez. Hoy, hay pocas cosas que duren y que den estabilidad a la vida y a las relaciones. Vivimos en un tiempo fragmentado, lo que Bauman (2006) Ilamó liquidez de la vida y las relaciones.

21 Esta inversión carnavalesca relacionada con la locura, las ánimas benditas y los santos inocentes no es exclusiva de la Fiesta de Verdiales. En toda la península ibérica, y más allá, está presente esta inversión en expresiones rituales populares. Concretamente, en Andalucía, la encontramos, por ejemplo, en los «cascaborras» o "cascamorras» en el altiplano granadino de Guadix, Baza, Puebla de Don Fadrique y otras localidades, en los grupos de animeros del sureste andaluz, en las cuadrillas de ánimas de Almería, en los "Locos» de Fuente Carreteros (Córdoba) y en los de Écija (Sevilla) (Del Campo 2020).
Hoy, todo queda bajo el dominio de la novedad, lo inmediato, la premura, y esto construye relaciones poco sólidas, poco durables y que construyan vínculos. Así, la expresión popular, muchas veces, choca con estas lógicas de la velocidad, la inmediatez.

En la última Fiesta Mayor de Verdiales tuvimos ocasión de observar cómo una turista del norte de España se deleitaba con la Fiesta, pero a la vez le intranquilizaba los tiempos del ritual, y apremiaba a los fiesteros a que no se demoraran entre lucha y lucha ${ }^{22}$, asociando la experiencia que estaba viviendo con los tiempos conocidos, medidos y previstos como los dispuestos en las lógicas de la rentabilidad del espectáculo. No entendía por qué, ni para qué, de esas demoras. "Os entretenéis mucho», sentenciaba la turista; no comprendiendo que la Fiesta es todo eso, además del cante, del toque y del baile; es decir, es el encuentro, el saludo, la charla, la copa, la broma, las risas compartidas.

Un elemento esencial de la Fiesta es la aparición de lo sorpresivo, lo espontáneo. En la dilatación del arranque aparecen momentos inusitados que van caldeando el inicio. Aquí tiene lugar lo insólito de encontrarse con alguien inesperado o, incluso, oír a alguien que toca, canta o baila de un modo peculiar o sorpresivo. El propio baile es un baile sin guion, «el baile en la Fiesta de Verdiales es espontáneo e improvisado, no está sujeto a un número determinado de compases y las mudanzas van variando» (Tomé 2010: 80). Incluso hay mudanzas que son recreadas por algunos bailaores de forma espontánea. En la Fiesta no gusta la uniformidad, así, cuando una pareja se dispone a bailar no sabe de antemano qué mudanzas van a ejecutar, no hay una estructura predeterminada de pasos y secuencias, como sí ocurre en el baile folclorizado. El baile «es espontáneo e improvisado, aunque macerado, y lo que transmite su mensaje es la manera en común de darle vida» (Tomé 2010: 84).

La Fiesta, como tiempo vernacular, se aprende en la Fiesta, es como un difuso ritual de iniciación. Las maestras y maestros fiesteros insisten en que «sólo se aprende Fiesta estando de Fiesta». No es algo que pueda aprenderse de forma externa a ella. Frente a

22 «Lucha, reveza, ganchá o roailla, se componen de una entrada de violín en paseo o subida, tres o cuatro coplas cantadas y, en ocasiones, otra "subida" de violín para terminar» (Molina 2010: 15). 
esto, cuando se está aprendiendo desde la lógica de la escritura a cantar, tocar, bailar, no se está tocando, bailando ni tocando realmente. El tiempo vernacular es tiempo sin fragmentar, es lo contrario a los tiempos líquidos (Bauman 2007), es tiempo asociado a los tiempos cíclicos (Debord 2003), tiempos vividos, frente al tiempo capitalista de la mercancía. Son tiempos nada asociados a la fragmentación industrial, a la fragmentación que exige la producción, la acción instrumental, que separa medios y fines. Los tiempos de la Fiesta no son tiempos fragmentados, sino continuos, propios de las lógicas expresivas en las que se establece una unidad de espacio y tiempo, así como de medios y fines (Gil Calvo 1991). En nuestro trabajo de campo etnográfico, un antiguo arriero (y fiestero) supo ejemplificarnos desde su memoria viva este otro tiempo expresivo, no instrumental, propio de la Fiesta.

"Antiguo arriero: En Comares, había uno que le decían Malandingo, del que se contaba que la mujer estaba muy mala, mala para morirse, de unas fiebres malta. Entonces, Malandingo, se subió en el mulo y salió para ir en busca del médico. Al pasar por Los Ventorros [pedanía próxima a Comares] escuchó Fiesta. Él no se bajó del mulo, pero los fiesteros salieron a la puerta a llamarlo: - ¿Hombre, Miguel, dónde vas?

- Ahí voy para el pueblo a buscar al médico que mi mujer se está muriendo, con unas calenturas para morirse.

- Anda hombre, bájate del mulo, echa un revecillo, te bebes un vasillo de vino y ya te vas.

- No hombre, icómo me voy a parar!

Total, que allí un rato porfiando que si te quedas que si me voy..., y dijo Malandingo:

- Bueno, me voy a bajar del mulo, pero más de tres días no estoy.

Y le sacaron una copla:

Cuando Fiesta le pedían

Decía Miguel Malandingo

Para un rato no me «empringo»

Pero no más de tres días

Viernes, sábado y domingo».
La expresión festiva es mucho más que el sedicente folclore: cante, música y baile. En la Fiesta es fundamental el encuentro, las indirectas, las ironías, insultos de doble sentido. La ironía, la broma, lo jocoso, es ambivalente. En este sentido, la Fiesta tiene un lado negativo (aniquilación, insulto, rebajamiento), y un lado positivo (renovación, desvelamiento de algo que no puede decirse de otro modo, de un modo unívoco). En los juegos del lenguaje populares no aparecen estáticos ni separados los aspectos positivos y negativos de la vida y sus relaciones. Porque son un zarandeo a lo que se presenta como verdad hegemónica, dominante (Bajtín 2003).

La rifa, por ejemplo, es un ritual exclusivo del ciclo del solsticio y ejemplo de este zarandeo que aludimos. En ella se desatan las presiones sociales que tienden a situar a los participantes «en su sitio». La rifa es una gozosa inversión de roles en la que «las pandas de tontos» cobran autoridad. Es una forma de juego profundo (Mandly y Llorente 2013), elemento estético imprescindible (Caro 2006) que lleva la fantasía al poder, transmitiendo vida al ritual. Hoy podemos encontrar las rifas en los dos primeros días de Pascua -25 y 26 de diciembre- en algunas ventas y bares de los barrios de las salidas de Málaga, sobre todo Ciudad Jardín y el Puerto de la Torre, o incluso en los mismos barrios periféricos de la ciudad donde habitan la gran mayoría de fiesteros que bajaron de Los Montes. Si bien la rifa no se produce ya como a principios o mediados del siglo $\mathrm{XX}$, sigue estando en los mismos cimientos de la Fiesta de «los Tontos». Por eso, en la Fiesta de Verdiales siempre están presentes, con la música y el baile, la broma, el doble sentido, la ironía, los juegos del lenguaje, en los que simbólicamente se altera el orden establecido. Cuando hablamos de estas bromas, ironías, inversiones, no nos referimos solo a momentos paralelos a las luchas de Fiesta, sino que en la propia ejecución del toque, el cante o el baile se pueden producir estas lógicas de carnavalización y juego. Así, hay toques de pandero, sobre todo entre algunos fiesteros antiguos (ver Figura 6), en los que se invierte completamente el instrumento a la hora de ejecutar su toque. O bien, cantan con una gesticulación casi grotesca y un tono de voz más propio de mujeres que de varones. También en el baile, ejecutándolo casi como un saltimbanqui que trisca alrededor de la mujer (pero sin perder los pasos de la mudanza). 


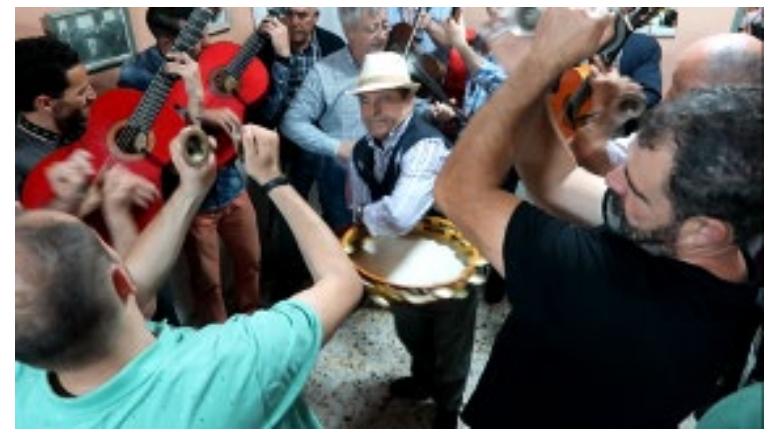

FIgURA 6.- Inversión simbólica. Fotografía de los autores.

La Fiesta, liberando del utilitarismo, abre las puertas a entrar en un universo utópico en el que los fines prácticos no son el eje (Bajtín 2003). El juego presenta de otro modo lo que es, lo que se vive, $y$, por tanto, abre nuevos horizontes de representación de la realidad y otros modos de vivirla. El ser humano pleno, según Nietzsche, en Así habló Zaratusta, es el que juega creando; el creador con el juego cuestiona lo fijado, lo dispuesto y lo establecido. La Fiesta, el juego, como expresión y comunicación de la comunidad, permite relacionarse de otro modo, incluso puede darle la vuelta a la Realidad (García Calvo 2002).

\section{LA EXPERIENCIA ESTÉTICA}

A partir de nuestro trabajo de campo etnográfico hemos llegado a entender la Fiesta de Verdiales como tiempo sublime. Con sublime (Saint Girons 2008) nos referimos a lo que está en el límite de la razón, que no puede conceptualizarse, categorizarse, pero que tiene el privilegio de mostrar lo que no es posible hacer visible de otro modo. Lo sublime es algo que está en el aire, que no se puede cuantificar, no se puede atrapar; es algo inasible que, paradójicamente, nos aferra. Nos atrapa lo no previsto, lo no preparado, lo no sabido. Lo sublime se caracteriza porque se disuelve, se diluye, se desvanece en el mismo momento que nos atrapa. En el caso de la Fiesta de Verdiales, cuando indagamos de dónde procede su adhesión, a veces se olvida el abordaje socioantropológico que ahonda en de qué "salva» la Fiesta, qué se encuentra en ella que hace que grupos sociales diferenciados (por edad, sexo, estrato social, etc.) que se expresan en distintos códigos sociales y existenciales, compartan y confluyan en esos instantes, y solo en ellos, del proceso ritual.
Los sujetos humanos tenemos una dimensión social. Solo podemos alcanzar una vida plena "con otros». Sin embargo, nuestras sociedades de consumo, para poder reproducirse, necesitan el olvido de esta dimensión, ahondando aún más en el individualismo. Pero las expresiones populares alimentan la dimensión social que tenemos los sujetos humanos y, quizá, sea, unido al ritmo, uno de los factores por los que agarra. Según Havelock «el ritmo en sus diversas modalidades es el fundamento de todos los placeres biológicos, de todos los placeres naturales, el sexo incluido y, posiblemente también, de los llamados placeres intelectuales» (1996: 105). Si esto es así, podemos entender el placer y emoción que nos producen los cantes, los toques y los bailes, imbricados con la topo y la temposensitividad. La Fiesta de Verdiales es una fuerza centrífuga, que invita, que atrapa. Su ritmo contagioso incita a celebrar de forma compartida, auspicia la experiencia estética que alimenta esa fuerza. Para Octavio Paz, cada sociedad posee un ritmo propio. El ritmo es «una actitud, un sentido y una imagen del mundo distinta y particular [...] [es] actitud espontánea del hombre ante la vida, no está fuera de nosotros, es nosotros mismos expresándonos en temporalidad concreta, vida humana irrepetible» (Paz 1981: 61).

"Hay como unas cuerdas internas que tenemos los fiesteros, todos nosotros que estamos aquí, que vibran cuando se producen determinados momentos en la Fiesta. Estas cuerdas vibran con unos puntos que entran a través de la métrica, del ritmo, pero sobre todo a través de las caras de los compañeros. ¡Eso es mágico! ». (Fiestero, 62 años).

En nuestro trabajo de campo hemos asistido a momentos en que la Fiesta está álgida, «está en la última lavija», como dicen los fiesteros. Es ahí cuando se produce una confluencia de ritmo, coplas, mudanzas (baile), miradas, bromas, que hacen que ese instante se desee eterno, de lo que se desearía quedar colgado. Vivir estos momentos sublimes exige exponerse expresivamente y ser anegado por la expresividad de los demás. Y esto hace que se recuerde ese instante como momento existencial memorable, que ayuda a soportar la rudeza de las lógicas sociales impuestas y que facilita seguir adelante vitalmente. Se trata de momentos inasibles, momentos inconmensurables, 
pero que perviven y construyen la memoria ${ }^{23}$ de la Fiesta.

En la Fiesta de Verdiales, los fiesteros y las fiesteras traen continuamente elementos del pasado al presente para autorepresentarse, y proponen esa memoria como la base sobre la que se configura el buen fiestero. Hay una continua alusión a la memoria de lo vivido, lo oído, que forma parte de la Fiesta. Encontramos una evocación continua de la memoria campesina, como si fuera un valor, aunque ya no esté vigente esa forma de vida. La expresión festiva «es una forma humana de juego mediante la que el hombre amplía y se apropia un sector de la vida, que incluye el pasado, insertándolo en su propia experiencia» (Cox 1983: 22).

«Eso es que mira, nosotros, en el campo. [...] Entonces, el ejero [...] en la yunta de mulos, tiene el arado y una cosa que nosotros le decimos el ejero, y el ejero tiene en la punta un boquete y si tú quieres que el arado hinque más en la tierra lo pones más para arriba, que quieres que hinque menos, pues lo pones más abajo. El ejero tiene a lo mejor cuatro boquetes [...] y entonces, si quieres que vaya más hondo lo pones en el último lavijero [último agujero], y entonces el surco es más grande y la labor es mejor. Por eso, nosotros decíamos "la fiesta está en el último lavijero",

23 Ricoeur (2003), distingue entre memoria y rememoración. Los griegos llamaban mneme al recuerdo pasivo que aparece (incluso llamaban pathos su llegada a la mente, indicando pasividad) y, por otra parte, anam-nesis designaba la rememoración, es decir, el recuerdo fruto de una búsqueda consciente. Acordarse es tener un recuerdo o ir en su búsqueda. Platón, cuando relata el nacimiento de la escritura en el Fedro, considera que la escritura, por el descuido de la memoria traerá el olvido, pues fiándose de la escritura se recordará de una manera externa, valiéndose de caracteres ajenos. Así, la escritura no será el elixir de la memoria, sino el elixir de la rememoración. Platón dirá que, en caracteres de escritura, no puede quedar reflejado un arte (saber) pues los decires escritos son solo un medio para recordar aquello sobre lo que versa lo escrito. La memoria tiene una estructura narrativa que se contrapone al mero almacenamiento. La memoria reelabora, recrea, por eso ancla, frente a los datos grabados, que permanecen iguales. Escribir y leer, como dice Walter Ong (1987), son actividades solitarias que inducen a la concentración en sí mismo. Frente a la oralidad, que propicia el desarrollo de aspectos más comunitarios y menos introspectivos. porque estaba buena, buena, buena. Y otra palabra que utilizamos también es la fiesta se ha puesto "reonda"» (Fiestero, 72 años).

La presencia de la memoria común y cateta aparece a través de estos juegos del lenguaje en los que late esa memoria, y que se expresa en el trasvase de elementos de la vida productiva de los campesinos de los Montes de Málaga a la Fiesta de Verdiales.

«-Fiestero: La yunta tiene dos camellas, la derecha y la izquierda. Entonces, hay mulos que son camelleros, que aran solo a la camella izquierda o a la derecha. El que ara a las dos camellas, ara lo mismo a un lado y a otro.

-Arriero: Por ahí arriba (en terrenos de campiña) aran a las dos camellas. Por ejemplo, araban hasta la hora de comer, los desenganchaban, descansaban y los cambiaban de camella y seguían arando, porque aran a las dos camellas.

-Fiestero: En esos tiempos tener un mulo camellero eran un plan, porque se te desgraciaba un mulo que a lo mejor araba a la derecha y tenías que buscar un mulo que arara en esa camella.

-Arriero: Pero los gañanes tenían siempre un mulo de pico. En estos "pechos" 24 , en los barrancos, los camelleros aran mejor. En la zona de campiña, en los llanos, ahí no, ahí no eran camelleros. En Colmenar mismo ya no eran camelleros, aquí en Colmenar, Casabermeja y Villanueva ya los mulos sí araban a las dos camellas.

-Fiestero: Todo eso tiene su significado, porque tú, por ejemplo, si estás hecho a tocar los platillos en el lado derecho se dice que eres de la camella derecha».

(Conversación entre antiguo arriero y fiestero de 60 años y su hijo, fiestero, de 35 años)

La Fiesta se convierte en un eje de la vida del fiestero y la fiestera, es una forma de entender y de estar en el mundo, es un modo de relacionarse anclado en vínculos sólidos construidos desde la

24 Según el Diccionario de la Lengua Española (DLE), «pecho», en su novena acepción, significa: cuesta bastante pendiente y no larga, repecho. 
memoria común, frente a la liquidez que presentan las relaciones sociales en nuestras sociedades.

«-Fiestero: El aparejo antiguo en nuestro terreno llevaba: primero un ropón, después el "alabardón", después otro ropón, después las almas. Las almas que iban llenas de pajas y se le subía la paja para arriba [...] y luego llevaba otro ropón y la "sobrealma". La "sobrealma" era ya lo bonito del aparejo.

-Arriero: es que algunos mulos son fríos de lomo.

-Fiestero: Cuando a lo mejor se echaba 10, 12 o 14 luchas seguidas, mi compañero decía: "ahora ya se me está asentando el aparejo".

-Arriero: $\mathrm{Y}$ los fiesteros, en las primeras luchillas, dicen mucho "es que soy frío de lomo». Cuando "se le asienta el aparejo" es que la Fiesta se está empezando a poner buena».

(Conversación entre antiguo arriero y fiestero de 60 años y su hijo, fiestero, de 35 años)

La participación colectiva en las expresiones populares, refuerzan vínculos comunitarios, a la vez que sirven de momentos comunicativos y de catarsis colectivas y personales. Los modos de decir expresan ya modos de estar en el mundo, de entender la vida. Cuando se está diciendo se está diciendo y se está haciendo. Lo estético y lo moral están próximos. Expresan la necesidad de fuerza moral de base para que se produzca la experiencia estética deseable.

"Yo he estado con este [señala a otro fiestero platillero] y nunca le he podido decir "que me estás estorbando". Siempre me ha guardado el sitio. Cuando él se fue entró otro compañero que tocaba por lo alto mía. Eso es como una yunta de mulos. Como si un mulo se echa encima del ejero». ${ }^{25}$ (Fiestero, 72 años)

En estos juegos del lenguaje aparece viva la memoria campesina y sus relaciones, una y otra vez, como eje estético-moral que construyen comunidad ${ }^{26}$. Esta

25 El mismo fiestero aclara: «que se le echa encima el ejero quiere decir que se le viene el mulo encima del otro y el otro de abajo tiene que ir aguantándolo. Y el mulo de abajo va trabajando el doble».

26 Con esto no queremos decir que en la Fiesta de Ver- memoria es una memoria cateta, fiestera, construida desde las lógicas de la oralidad que, como señala Ong (1987), no tienen estos juegos como ocasionales, sino como incesantes, y conforman la sustancia del pensamiento mismo, consiste en ellos. Los valores estéticos, esos que Lavelle (1991) consideraba que constituían al hombre ante el mundo, se instituyen como valores morales y sociales. Comprender la Fiesta exige una mirada sobre la representación compartida que se construye desde la experiencia estética, "de sonidos que son sentidos a través de la acción, del ritmo, de la copla que te sacude como un relámpago en el brocal del mundo desde donde se habla» (Mandly 1996: 19).

\section{LA DYNAMIS EN LA FIESTA}

Hoy, con frecuencia, vemos la expresión popular transformada en eventos, en espectáculos. Con espectáculo no nos referimos tanto a lo escenificado, sino a la lógica del espectáculo fundada en la afirmación de la apariencia que, en palabras de Debord, es «la negación visible de la vida, como una negación de la vida que se ha tornado visible» (Debord 2003: 40).

"Evento» viene de eventus, y significa lo que se produce de repente, lo que no tiene anclaje, que está desenclavado. La eventualidad es lo contrario de la necesidad del tiempo sublime, tiempo con aroma, con narración que crea sentido, un tiempo en el que acontece algo (impreciso, imprevisto, inasible), tiempo colmado, tiempo pleno. El espectáculo representa un fragmento separado y se muestra como una realidad cerrada, frente a la compleja, ambivalente e inconclusa realidad expresiva, que debiera abordarse como totalidad abierta (Fabbri 2004). La fragmentación espectacular niega la ambigüedad, la complejidad, por eso es un fetiche, una necrópolis de la realidad expresiva.

En nuestras sociedades tiene valor lo expuesto, lo que acapara la atención (que cada vez es más dispersa y necesita de novedades continuas para seguir estimulando los sentidos). «El espectáculo

diales solo existan estos valores comunitarios, pues no está exenta de las influencias de la sociedad en la que estamos. Sin embargo, queremos resaltar que, en los momentos rituales de la Fiesta, prevalecen los elementos comunitarios sobre los individuales, mercantiles, de consumo, etc. 
constituye el modelo actual de vida socialmente dominante» (Debord 2003: 39). Se selecciona lo que se puede espectacularizar, mostrar y rentabilizar. La exposición transforma todo en mercancía que queda disponible desde ese momento en algo que, más que vivido, puede ser consumible/do.

La Fiesta de Verdiales cumple con el principio de la expresión festiva que aúna la comunicación de la comunidad, el reconocimiento y la autorreferencia de esta, así como su expresión. En ella los intereses individuales quedan transmutados en intereses comunitarios, del común. El mismo concepto de «arrejuntaos» ${ }^{27}$ ya invita a las relaciones sociales con los otros, a compartir desde y para el común. Durante una de las entrevistas en profundidad desarrolladas en el trabajo de campo uno de los informantes nos narraba cómo, a veces, algunos fiesteros decían «no toco más con este porque no me da mi sitio». Según nuestro informante, «nadie se puede imponer a nadie, si no la Fiesta se estropea». Es contrario a la Fiesta. Este "no me da mi sitio», no es tanto la demanda de reconocimiento de valía y habilidades, como una llamada a que es necesario dejar ser y estar a cada uno para que cumpla su función (compartida) en el grupo. Es una demanda a dejar a cada sujeto ser parte integrante del todo, del grupo, de la panda. Aquí no prima el yo moderno instituido como individuo y sus lógicas de relación, sino que se exige la disolución de este.

La fiesta exhibe una ambigüedad interesante, es vehículo de reconocimiento de los sujetos, pero «por» y «con» el grupo. Así, «solo quien ha estado sujeto a la fiesta asume el poder de ser también sujeto de ella» (Gil Calvo 1991: 126). La experiencia expresiva festiva se vive desde la sujeción interpersonal, desde el vínculo efectivo con los otros, un vínculo instituido por lo que Gil Calvo denomina «heteronomía expresiva», es decir, comunitaria. Esta sujeción es la que puede generar las experiencias que algunos de nuestros informantes califican de mágicas.

Turner (1998) nos ponía sobre aviso de que los rituales expresivos vinculan de un modo excepcional a los miembros de la comunidad (por encima de las

27 En la Fiesta suelen reunirse en «pandas de arrejuntaos» fiesteros que pertenecen a distintas pandas formales. La clave de estos grupos de "arrejuntados» es que no pueden formar parte de ellos más de dos fiesteros de una misma panda. divisiones y diferencias que establece la estructura social). A nuestro modo de ver, y según nuestra etnografía, esta comunicación de la comunidad puede llegar a configurarse desde la «conversación».

«La conversación ofrece una afinidad peculiar con la amistad. Solo en la conversación (y en la risa común, que es como un consenso desbordante sin palabras) pueden encontrarse los amigos y crear ese género de comunidad en la que cada cual es él mismo para el otro, porque ambos encuentran al otro y se encuentran a sí mismos en el otro». (Gadamer 1998: 206)

Cuando hablamos de "conversar» nos referimos a la dimensión de esta como fuerza transformadora. Conversar, más que una actividad individual, es una actividad performativa de lo colectivo. $Y$ sin escucha, no hay conversación. Escuchar no es un acto pasivo ni narcisista. «Escuchar es un prestar, dar, un don. Es lo único que ayuda al otro a hablar» (Han 2017: 113). En la conversación nos vaciamos, nos redimimos, somos acogidos, reconocidos, nos reconciliamos con nosotros, incluso, puede sanarnos. El oyente como oyente, se vacía de su individualidad para reconocer al otro. El oyente se pone a merced del otro, esta forma de sujeción al otro nos relativiza. El ego del individuo no escucha, está demasiado imbuido en el ruido, en el intercambio acelerado de informaciones, no entabla una relación, solo conexiones. El tiempo del otro se vive como un tiempo improductivo para el yo, y esto viene acompañado de la totalización, de la producción en todos los ámbitos vitales que conduce a una explotación y autoexplotación de las personas. Desde este sentido, también queda eliminado el tiempo de la Fiesta, el tiempo sublime, que no puede ser sometido a la lógica de producción y la rentabilidad. El tiempo del otro en la Fiesta, clave en la escucha y en estas formas de comunicación expresiva, crea comunidad, frente al tiempo instrumental y frente al tiempo del yo, del individuo. En la Fiesta, somos «con» otros.

"Yo me acuerdo que hace unos años estábamos de Fiesta y vinieron los cuatro viejos de la panda, que le decían los cuatro magníficos, porque el compás de platillos que formaban los cuatro, parecía que ibas en volandas, como que te llevaban en hombros. Había también un chaval y le dejaron echar a ese muchacho una luchilla de platillos. Cuando 
terminó la lucha echamos un rengue ${ }^{28}$. Y entonces le dije, ¿tú de verdad has valorado esa lucha que has echado? Y se volvió y me dijo, "a mí me da igual". Así me lo zampó y cogió y se quitó de en medio. La primera vez que yo toqué con aquellos hombres, recuerdo que me temblaban hasta los tobillos, de lo hondo hasta arriba, no daba crédito». (Fiestero, 35 años)

Esta etnografía pone de manifiesto que el baile, el cante, el toque..., de la Fiesta se sustraen del principio de rendimiento (no tienen una "utilidad», un fin, se agota en sí mismo). Se reúnen para disfrutar juntos y unos de otros, para "echar Fiesta», cantando, bailando, tocando y con ánimo de aportar. Es un disfrute compartido, participando y aportando. Los informantes hablan de "meter mano a tocar Fiesta», como símil para hacer un trabajo en común. De hecho, "echar un revezo" ${ }^{29}$, es como se denomina en la Fiesta a "echar unas luchas». En la Fiesta es posible encontrar una comunidad, un "cuidado mutuo». Lo verbalizan y manifiestan los fiesteros y las fiesteras a través de su comportamiento.

En la Fiesta se relacionan del mismo modo niños, jóvenes y mayores. Hay una comunicación intergeneracional. Estando muy presentes valores como el respeto a los mayores, todos por igual reciben trato y reconocimiento, participando de igual a igual y con el mismo peso en los rituales. Esta participación horizontal es una forma de relación que va a contrapelo, a orza, de las relaciones sociales construidas desde el capital y el consumo. Contrariamente a lo que pueda parecer, la lógica del consumo, para Baudrillard (2009), no es una lógica individual de satisfacción, sino una lógica social de diferenciación. La Fiesta puede "salvar», a la vez, a unos de la explotación (antes y ahora), y de la vaciedad vital de las lógicas del consumo (que no son lógicas de explotación).

Las lógicas de relación en la Fiesta van a contramano de esas lógicas de diferenciación, de explotación y estratificación. En la Fiesta hay una liberación de las reglas y coacciones del mundo oficial, de sus

28 Un rengue de la Fiesta es una "humailla» [de un cigarro, como echar un cigarro], un descanso.

29 «Echar un revezo» significa, según el Vocabulario andaluz de Alcalá Venceslada de 1934, «ayudar a uno en su faena». preocupaciones y de su seriedad. Esa liberación es «el derecho de ver el mundo con los ojos de la tontería» (Bajtín 2003: 234) que conecta con la parte popular de otras fiestas. Así, se puede considerar como formas de respiro, de desahogo y de resistencia (Castells 1997), que solo pueden darse desde las lógicas de comunidad.

\section{CONSIDERACIONES FINALES}

La fiesta emancipa de ataduras externas y crea lazos internos (vínculos libres) desde la normatividad consuetudinaria de la propia fiesta; pero también redime porque libera del poder que ata disciplinariamente al orden microsocial (familia, amigos, comunidad,...) y al orden macrosocial (sistema económico, social, político,...). La fiesta salva momentáneamente y de forma simbólica del control social. Por eso la fiesta produce vértigo, vértigo que se diluye porque se sabe de su fin, de sus límites, instaurado por el fin de la fiesta.

Las expresiones populares festivas, como comunicación y expresión de lo que es común, de la comunidad, del tiempo sublime, de ese tiempo inasible en el que tienen lugar instantes eternos, nos posibilita afirmar dimensiones del tiempo y de la vida que en circunstancias ordinarias tememos, ignoramos o negamos. En ellas, el cometido expresivo se antepone al instrumental y nos ayuda a imaginar la Realidad de otro modo, de un modo más humano, de un modo más vincular. Expresiones populares como la Fiesta de Verdiales muestran los pies de barro de la Realidad, su debilidad, y por eso provoca risa, abriendo vías a la posibilidad de su transformación.

La Fiesta actúa sobre disfuncionalidades del tejido social, actúa retejiendo vínculos y lazos que el individualismo, como ideología, destruye. La Fiesta reproduce y, a la vez, pone en cuestión. Este ejercicio abre puertas a la posibilidad de configuración de un nuevo orden social, aunque la Fiesta, por sí misma, no lo construya, solo presenta su posibilidad simbólicamente. La Fiesta, haciendo olvidar lo que de individuos tenemos los sujetos, empuja a vivirla desde lo que "de común» tenemos. Es decir, muestra como viable, aunque sea simbólica y momentáneamente, lo que no lo es fuera de ella.

Sin embargo, la expresión popular no debe pensarse como reminiscencias del pasado que se replican, que se reproducen en un intento imposible de fidelidad a 
una raíz primigenia inalterable a lo largo del tiempo, que queda recluida en unos lugares concretos sin modificarse y mutarse. La expresión festiva es algo vivo, algo que para mantenerse ha de tener funciones nuevas y significaciones sociales para el grupo, hoy. Es decir, para mantenerse debe estar vinculada con el presente de la comunidad, porque es expresión social de esta.

No podemos mitificar lo que ofrece la Fiesta, pues estos rituales expresivos también muestran contradicciones. Como dice Gil Calvo, todo comportamiento festivo "exhibe alguna clase de contradicción, sea lógica, sintáctica, o pragmática» (1991: 192). Así, encontramos en los rituales catetos de la Fiesta la broma, los juegos del lenguaje (anclados en la memoria campesina), juegos de inversión de roles (las denominadas "relaciones», las rifas,...). Estas "carnavalizaciones», como las llama Antonio Mandly (2017), muestran la doble faz de la expresión festiva. Son formas de inversión, de transgresión simbólica del orden establecido; sin embargo, no lo niegan ni proponen un nuevo orden, más bien muestran su debilidad, ponen en evidencia su vulnerabilidad, sus pies de barro. La Fiesta reproduce la estructura social, sus estratificaciones, sus desigualdades, sus segmentaciones y, a la vez, difumina jerarquías, crea relaciones y vínculos entre grupos sociales, sexos y generaciones que fuera de ella aparecen disgregados. Hoy, el mundo lo llenamos de eventos cada vez más breves, más desanclados de sus contextos de significación. Eventos que compiten desde la lógica mercantil. Compiten por tener una presencia mayor en los medios de comunicación, compiten por tener una presencia en internet, en las redes sociales.

La Fiesta, como ya hemos señalado, ha cambiado, sobre todo, en aspectos externos que algunos sectores fiesteros (por ahora minoritarios) se empeñan en potenciar al albor de estas lógicas. Nos referimos concretamente a la progresiva espectacularización que la Fiesta está sufriendo desde las últimas décadas. La escenificación, que dispone a la panda en línea, atenta contra elementos genuinos descritos más arriba, como la disposición de la panda y los círculos concéntricos de los participantes en el ritual, la entrada y salida de fiesteros al círculo, la imposibilidad de la comunicación no verbal (imprescindible para alcanzar momentos sublimes), etc. Esta espectacularización se sostiene buscando en la Fiesta nichos laborales a través de la patrimonialización de la misma. Signos de este proceso los encontramos, por ejemplo, en el empeño en que las pandas adopten un uniforme, en que se quiera establecer que solo "titulados» de música y danza puedan impartir clases en las escuelas de Verdiales (terminando así con la transmisión oral a través de maestros y maestras fiesteras, que la mayoría de las escuelas actuales sostienen), en exigir la fiscalización de las escuelas, o en los intentos por parte de determinadas instituciones de promocionar la Fiesta como si de un producto mercantil se tratara. Expresiones festivas populares como la Fiesta de Verdiales pueden caer rendidas a estas lógicas, que serían su sepultura, o, por el contrario, convertirse en formas de resistencia para vivir más humanamente.

\section{BIBLIOGRAFÍA CITADA}

Bajtín, Mijail. 2003. La cultura popular en la edad media y el renacimiento. El contexto de François Rabelais. Madrid: Alianza Editorial.

Bateson, Gregory. 1998. Pasos hacia una ecología de la mente. Una aproximación revolucionaria a la autocomprensión del hombre. Buenos Aires: Lohlé Lumen.

Baudrillard, Jean. 2009. La sociedad de consumo. Sus mitos, sus estructuras. Madrid: Editorial Siglo XXI.

Bauman, Zigmunt. 2006. Vida líquida. Barcelona: Paidós.

Bauman, Zigmunt. 2007. Tiempos líquidos. Vivir en una época de incertidumbre. Barcelona: Tusquets.

Blanco, Rafael. 1997. Un modelo de hábitat rural: El lagar de los Montes de Málaga. Málaga: Diputación de Málaga.

Caro, Julio. 2006. El carnaval. Madrid: Alianza Editorial.

Caro, Rodrigo. 1978. Días geniales y lúdricos. Madrid: EspasaCalpe.

Castells, Manuel. 1997. La era de la información. Economía, sociedad y cultura. Vol. II: El poder de la identidad. Madrid: Alianza Editorial.

Cox, Harvey. 1983. Las fiestas de locos. Madrid: Taurus.

Debord, Guy. 2003. La sociedad del espectáculo. Valencia: PreTextos.

Del Campo, Alberto (2020). El rito y la risa. Ensayos sobre la burla en la religión cristiana. Madrid: Mitáforas.

Dumont, Louis. 1987. Ensayos sobre el individualismo. Una perspectiva antropológica sobre la ideología moderna. Madrid: Alianza Editorial.

Fabbri, Paolo. 2004. El giro semiótico. Las concepciones del signo a lo largo de la historia. Barcelona: Gedisa.

Gadamer, Hans Georg. 1998. Verdad y Método. V. II. Salamanca: Editorial Sígueme.

García Calvo, Agustín. 2002. Contra la Realidad. (Estudios de lenguas y de cosas). Madrid: Lucina. 
Gil Calvo, Enrique. 1991. Estado de fiesta: feria, foro, corte y circo. Madrid: Espasa-Calpe.

Gómez, María Luisa y Rafael Blanco. 2010. «Los Montes de Málaga. Un hábitat identitario. La deuda de una ciudad con su área de influencia». Revista Jábega 103: 125-138.

Han, Byung Chul. 2017. La sociedad del cansancio. Barcelona: Herder.

Havelock, Eric A. 1996. La musa aprende a escribir. Reflexiones sobre oralidad y escritura desde la antigüedad hasta el presente. Barcelona: Paidós.

Lavelle, Louis. 1991 [1955]. Traité des valeurs. Traité des valeurs: tomo I, Théorie générale de la valeur, y tomo II, Le système des différentes valeurs. Paris: PUF.

Mandly, Antonio. 1996. Echar un revezo. Cultura: razón común en Andalucía. Málaga: Centro de Ediciones de la Diputación de Málaga (CEDMA).

Mandly, Antonio. 2010. "Los verdiales, un ritmo mediterráneo de solsticio». Revista Jábega 103: 27-47.

Mandly, Antonio y Francisco M. Llorente. 2013. "Jugar con fuego. Flamenco, juegos de lenguaje y tecnologías de la comunicación». Revista Gazeta de Antropología 29(1), artículo 07: 1-15.

Mandly, Antonio. 2017. "Toposensitividad, memoria honda y carnavalización. Funciones sociales y procesos de transculturación". IV Encuentro Mil formas de mirar y hacer. Artes, memoria y comunidad: 44-52. Sevilla: Universidad Pablo de Olavide.

Mauss, Marcel. 2009. Ensayo sobre el don: forma y función del intercambio en las sociedades arcaicas. Madrid: Katz Editores.
Molina, José Manuel. 2010. «La Fiesta: aspectos musicales, instrumentales y modalidades. El verdial de Los Montes: ritos y compas». Revista Jábega 103: 3-25.

Ong, Walter J. 1987. Oralidad y escritura. Tecnologías de la palabra. México: Fondo de Cultura Económica.

Paz, Octavio. 1981. El arco y la lira. El poema, la revelación poética, poesía e historia. México: Fondo de Cultura Económica.

Pitt-Rivers, Julian. 1979. Antropología del honor o política de los sexos. Barcelona: Editorial Crítica.

Real Academia Española. 2001. Diccionario de la Lengua Española. Madrid: Espasa-Calpe.

Ricoeur, Paul. 2003. La memoria, la historia, el olvido. Madrid: Trotta.

Rubio, María José y Jesús Varas. 1999. El análisis de la realidad en la intervención social. Métodos y técnicas de investigación. Madrid: CCS.

Saint Girons, Baldine. 2008. Lo sublime. Madrid: La balsa de la Medusa.

Tomé, Carmen. 2010. La difícil descripción de un baile sin guion. Revista Jábega 103: 75-85.

Turner, Victor. 1998. El proceso ritual. Madrid: Taurus.

Watzlawick, Paul. et al. 2002. Teoría de la comunicación humana. Barcelona: Herder.

Wittgenstein, Ludwing. 2010. Investigaciones filosóficas. Barcelona: Editorial Crítica.

Wölfflin, Heinrich. 1979. Conceptos fundamentales en la historia del arte. Madrid: Espasa-Calpe. 